\title{
Glass/Polyvinyl Chloride Composites
}

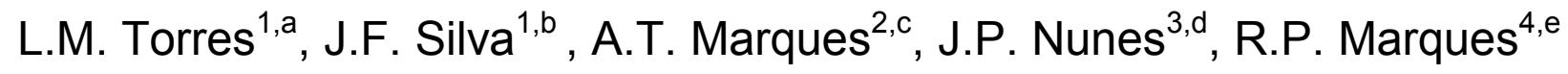 \\ ${ }^{1}$ Department of Mechanical Engineering, ISEP, Porto, Portugal \\ ${ }^{2}$ DEMEGI, INEGI, FEUP, Porto, Portugal \\ ${ }^{3}$ Polymer Engineering Department, University of Minho, Guimarães, Portugal \\ ${ }^{4}$ Companhia Industrial de Resinas Sintéticas, CIRES, S.A., Estarreja, Portugal \\ almt@isep.ipp.pt, ${ }^{b}$ jfs@isep.ipp.pt, ${ }^{c}$ marques@fe.up.pt, ${ }^{d}$.jpn@dep.uminho.pt, \\ rogerio.marques@cires.pt,
}

\begin{abstract}
Keywords: PVC, Thermoplastic composites, Glass fibre reinforced pipes, Filament winding, Pipe repairing
\end{abstract}

\begin{abstract}
This paper summarizes the results obtained in the use of plastisols of vinyl chloride homopolymer (PVC), obtained by the process of emulsion polymerization, as thermoplastic matrix in the production of composite pipes and in pipe repairing. Two processing techniques commonly used with thermosetting matrices were studied: filament winding and hand lay-up. The produced composite structures of PVC reinforced with glass fibres were subsequently subjected to tests in order to determine their mechanical properties. This paper concludes that it is possible to use the described technique for piping repairing with good results.
\end{abstract}

\section{Introduction}

Polymeric matrix composite materials are being increasingly used in different industrial and commercial applications, particularly in the automotive, aerospace and military markets [1, 2]. In these markets, they have been replacing with advantage metallic materials, particularly in the manufacture of structural components. Polymeric matrix composite materials can be divided in thermosetting or thermoplastic matrix based composites. The latter has important advantages, including increased toughness and damage tolerance, increased durability and the possibility of reprocessing and recycling. These advantages seem to justify a stronger growth rate in the applications of this type of matrices [3].

This article seeks to present some developments already achieved with the use of plastisols of vinyl chloride homopolymers (PVC) as matrix in the manufacture of composites reinforced with glass fibres (GF).

The plastisol with homopolymer VICIR E 1270P is a dispersion of PVC polymer particles, obtained by the processes of polymerization in emulsion using liquid organic plasticizers. This plastisol is characterized by its expanding behaviour at high cutting speeds, by a low initial viscosity and low aging.

Raw-materials. In this study a glass fibres 2400 Tex 357D-AA, produced by Owens Corning and a plastisol of vinyl chloride homopolymer (ref. VICIR E1270P), produced by Companhia Industrial de Resinas Sintéticas, CIRES, S.A. were used to produce pipes by filament winding.

It was also used a glass woven type E (ref. ROVITEX 163/100) impregnated with the PVC plastisol for PVC pipe repairing using the hand lay-up process.

Table 1 resumes the properties of the used glass fibre, obtained in a previous work [3]. 
Table 1. Raw material properties.

\begin{tabular}{l|c|c}
\hline \multicolumn{1}{c|}{ Property } & Units & Glass Fibre \\
\hline Density & $\mathrm{Mg} / \mathrm{m}^{3}$ & 2.56 \\
Tensile modulus & $\mathrm{GPa}$ & 62.5 \\
Poisson ratio & - & 0.26 \\
Tensile strength & $\mathrm{MPa}$ & 1170 \\
Fibre diameter & $\mu \mathrm{m}$ & 13.7 \\
Linear roving weight & $\mathrm{Tex}$ & 2400 \\
\hline
\end{tabular}

The PVC emulsion homopolymer Vicir E 1270 used in this work has a particle size distribution usually in the range between $0.1 \mathrm{e} 2 \mu \mathrm{m}$.

Production of PVC/GF composite pipes. The homopolymer of PVC was used to impregnate the glass fibres in the production of composite pipes by filament winding. For the plastisol preparation $50 \mathrm{phr}$ of plasticizer and a thermal stabilizer were used.

The piping production process starts by the impregnating of the glass fibres by the PVC plastisol, followed by its winding around a circular mandrel using a filament winding equipment with numerical control. The polymer reticulation and consolidation were done with a hot-air heater. Reticulation of the plastisol during piping production was controlled by measuring its surface hardness, which, according to the manufacturer information, must be above 80 Shore A. This process (Fig. 1) has the advantage of being automatic and capable to be easily implemented in an industrial scale.

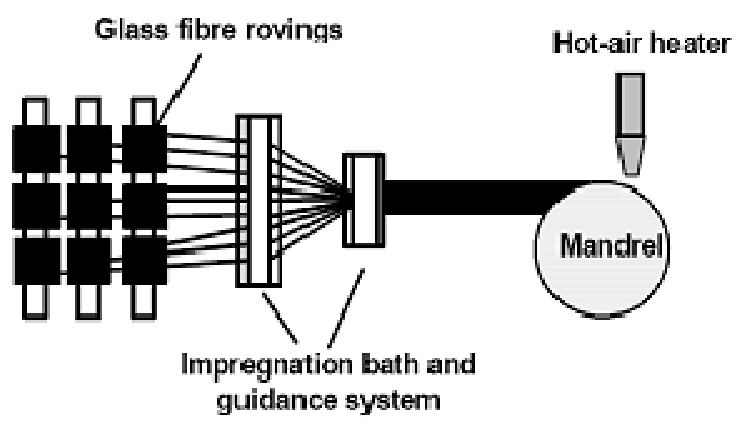

Fig. 1. Schematic diagram of PVC/GF piping production by the filament winding process.

By this way, several PVC/GF pipes were produced for testing, having $80 \mathrm{~mm}$ of internal diameter and approximately $3 \mathrm{~mm}$ of wall thickness. The winding angle used was circumferential $\left(\approx 89^{\circ}\right)$.

Mechanical properties. The determination of mechanical properties was done by testing tubular ring specimens that were cut from the produced pipes, according to ASTM D 2290-92. This test, designated as split-disk (Fig. 2), consists in submitting tubular rings to a stress field similar to the one developed by pipes subject to internal pressure tests. It is possible to determine experimentally the value of the tensile strength of PVC/GF composite pipes, $\sigma_{\theta}(\mathrm{MPa})$, using Eq. 1:

$$
\sigma_{\theta}=F /(2 l e) .
$$

where, $F(\mathrm{~N})$ is the rupture load recorded in the test, $l(\mathrm{~mm})$ is the width of the ring and $e(\mathrm{~mm})$ is its thickness. 


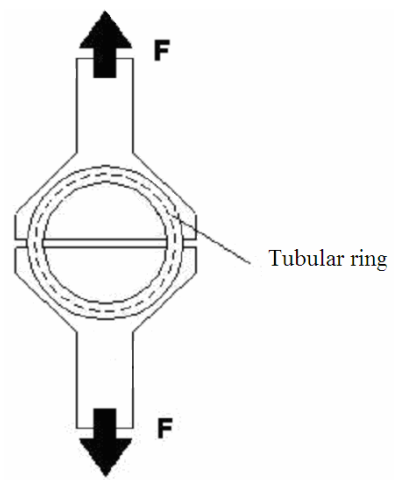

Fig. 2. Schematic diagram of the split-disk test.

The experimentally obtained average result for the tensile strength, using five test specimens, was approximately $110 \mathrm{MPa}$.

The results from these tests allow to establish, using Eq. 2 the pipe burst pressure:

$$
\sigma_{\theta}=\frac{p_{i} r_{i}}{r_{e}-r_{i}}
$$

where, $p_{i}(\mathrm{MPa})$ is the applied internal pressure, $\sigma_{\theta}(\mathrm{MPa})$ the circumferential stress in the pipe wall, $r i(\mathrm{~mm})$ the pipe internal radius and, $r_{e}(\mathrm{~mm})$ its external radius.

Based on studies developed previously $[5,6]$ and in order to verify the quality of the composites consolidation, the shear test device shown in Figure 3 was used to determine the interlaminar shear stress. Four samples obtained from the produced pipes, with $11.5 \times 7.5 \times 4.0(\mathrm{~mm})$, were tested.

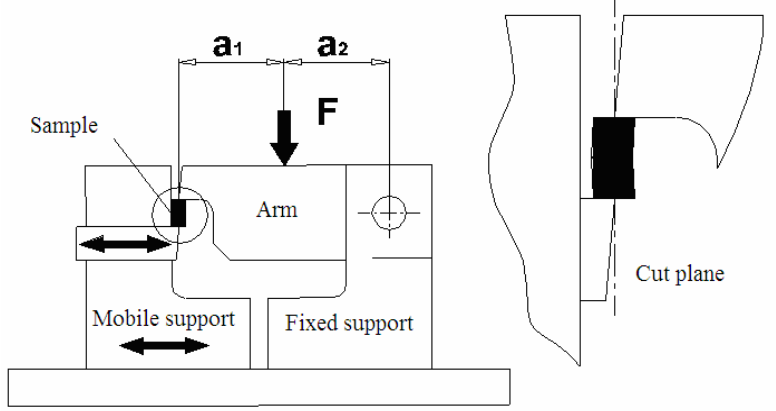

Fig. 3. Schematic diagram of the shear stress test device.

The samples were placed between the fixed support and the arm (Fig. 3). The mobile support moves to ensure the alignment of the edges that define the cutting plane. The load is applied by a universal mechanical testing machine in the middle of the arm of the device, subjecting the sample to an shear stress state. The interlaminar shear strength, $\tau_{r}(\mathrm{MPa})$ was determined by dividing the maximal load applied by the shear section area, as defined in the Eq. 3:

$$
\sigma_{r}=F\left(\frac{a_{2}}{a_{1}+a_{2}}\right) \frac{1}{l h} .
$$

where, $F(\mathrm{~N})$ is the maximal applied load, $a_{1}$ e $a_{2}(\mathrm{~mm})$ are the distances showed in Fig. $3, l(\mathrm{~mm})$ is the width of the sample and, $h(\mathrm{~mm})$ is the height of the sample.

The average value for the interlaminar shear strength, determined from the obtained experimental results, was $1.6 \mathrm{MPa}$.

Samples taken from the produced pipes were also observed under the scanning electron microscope JEOL JSM-6301F (Fig. 4), in order to study the impregnation quality. 


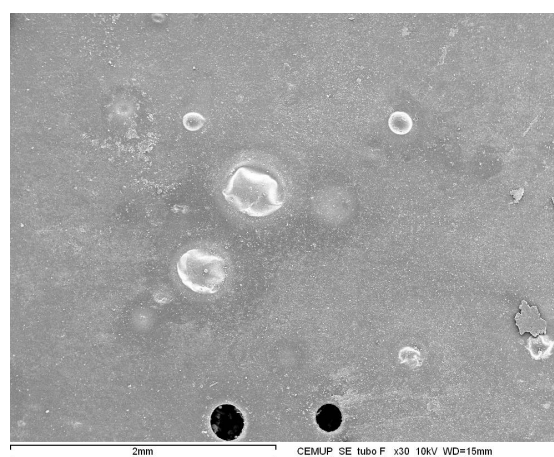

a) External surface

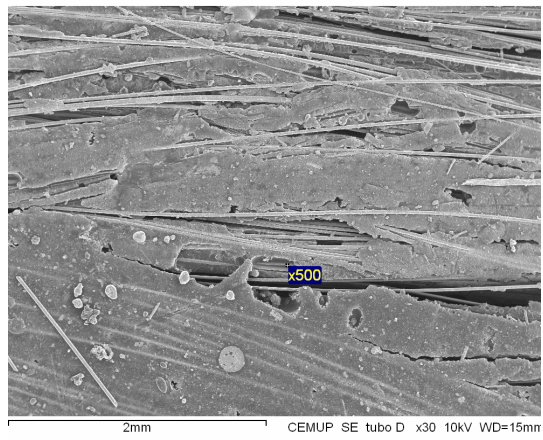

b) Internal surface

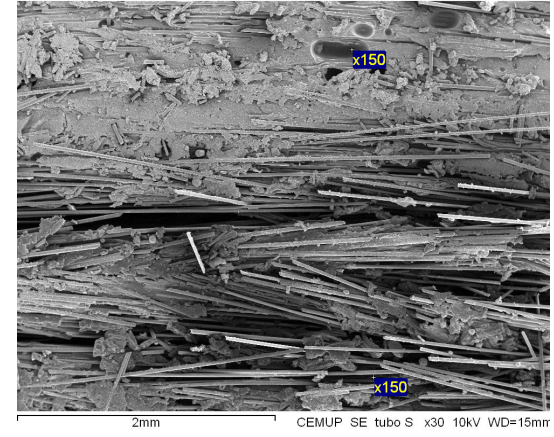

c) Cross section

Fig. 4. PVC/GF samples under SEM (approx. 30×)

Through the observation of the images collected, it can be seen that the external surface of the samples (Fig. 4a) are completely filled by the thermoplastic matrix, with some evidence of small particles of the plastisol additives and some dark circular spots that correspond to voids. These polymer particles can be minimized with better preparation of the plastisol before the application. From the observation of obtained micrographs, it can be concluded that the void content is typically lower than $2 \%$.

In the inner surface of the samples (Fig. 4b) some uncoated glass fibre filaments are visible, possibly due to the slight tension that the fibres are subjected in the pipes filament winding production process. This can be changed with the deposition of a thin layer of PVC plastisol on the mandrel before the fibre winding.

Finally, in the cross section of the sample (Fig. 4c) it is possible to identify two distinct areas: one, at the bottom of the image, corresponding to the inner layers of the pipe, with less resin content and the other, at the top of the image, which corresponds to the outer layers of the pipe, with a much higher resin content.

Table 2 summarizes the obtained results for the mechanical tests carried out on pipes produced by filament winding.

Table 3 exhibits typical properties of non-reinforced PVC. As can be seen, PVC composite mechanical properties are much higher than those of the non-reinforced PVC.

Table 2. Results of mechanical tests obtained from PVC/GF composite pipes

\begin{tabular}{c|c|c|c|c|c}
\hline \multicolumn{2}{c|}{$\begin{array}{c}\text { Interlaminar shear } \\
\text { strength }\end{array}$} & Tensile strength & \multicolumn{2}{c}{ Burst pressure } \\
\hline \multicolumn{2}{c|}{ [MPa] } & \multicolumn{2}{c}{ [MPa] } & \multicolumn{2}{c}{ [MPa] } \\
Average & St. dev. & Average & St. dev. & Average & St. dev. \\
1.6 & 0.04 & 111.5 & 8.0 & 14.6 & 1.6 \\
\hline
\end{tabular}

Table 3. Typical mechanical properties of PVC

\begin{tabular}{c|c|c}
\hline $\begin{array}{c}\text { Interlaminar shear } \\
\text { strength }\end{array}$ & Tensile strength & $\begin{array}{c}\text { Burst pressure of PVC } \\
\text { pipes }\end{array}$ \\
\hline$[\mathrm{MPa}]$ & {$[\mathrm{MPa}]$} & {$[\mathrm{MPa}]$} \\
12.0 & 25.0 & 2.5 \\
\hline
\end{tabular}


PVC pipes repairing. A technique capable of being used for structural PVC pipe repairing was also developed.

In this study, PN10 PVC pipes with $90 \mathrm{~mm}$ of external diameter and $1.5 \mathrm{~mm}$ of thickness were used. The damage was simulated by drilling circular holes with $10 \mathrm{~mm}$ of diameter. The repair was done with a composite patch of 3 layers of a glass fibre woven impregnated with the PVC plastisol by a technique similar to that commonly used with thermosetting composites (hand lay-up).

An electric heater (hot air heater) was used to consolidate the PVC matrix.

To test the efficacy of this repair technique, burst internal pressure tests were done. Three undamaged pipes and three repaired pipes were tested in order to compare the burst behaviours.

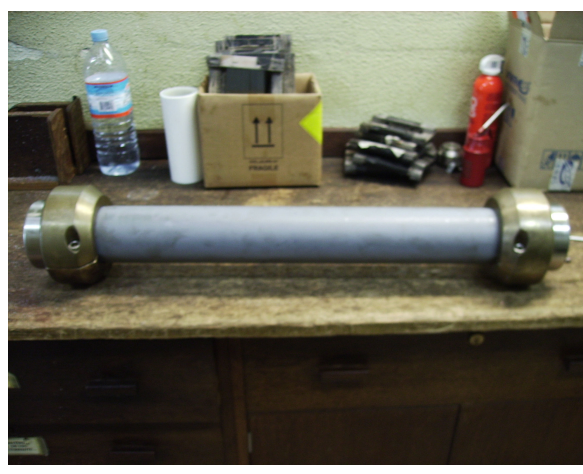

a) Pipe preparation for the internal pressure test

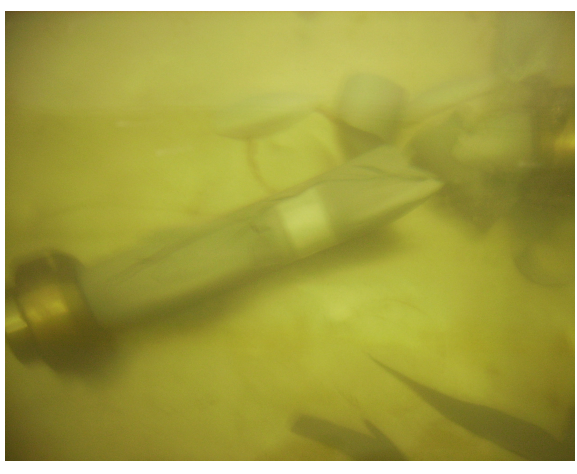

b) Burst of a repaired pipe during the internal pressure test

Fig. 5.Burst pressure tests

After preparing the pipe samples with type A terminals (Fig. 5a), they were tested with water at a temperature of $20.1^{\circ} \mathrm{C} \pm 0.09$ in a tank using a pressurized equipment, model Reglerautomatik Master RPCs 2. The internal pipe pressure was gradually increased until burst.

It was possible to determine that the average burst pressure of the three repaired pipes $(2.29 \mathrm{MPa})$ is comparable with the one of undamaged ones $(2.52 \mathrm{MPa})$.

Conclusions. The following conclusions can be taken from this work: i) a low viscosity plastisol of PVC can be used as matrix in the manufacture of composite material structures by filament winding; ii) the mechanical properties obtained in the GF/PVC filament wound composite pipes are compatible with many engineering applications, specially if it's specific values were considered and, iii) the repairing technique described in this paper can be applied for the reparation of damaged PVC pipes without significantly decrease their internal pressure resistance.

Acknowledgments. The authors wish to thank CIRES - Companhia Industrial de Resinas Sintéticas S.A., for kindly supplying the PVC samples used in this work.

\section{References}

[1] The Research Requirements of the Transport Sectors to Facilitate an Increased Usage of Composite Materials, Part I - The composite materials research requirements of the aerospace industry, EADS Deutschland GmbH (2004).

[2] The Research Requirements of the Transport Sectors to Facilitate an Increased Usage of Composite Materials, Part I - The Composite Materials Research Requirements of the Automotive Industry, Centro Ricerche Fiat (2004). 
[3] S. C. Fonseca: Characterization of Interfaces in Thermoplastic Composites Reinforced with Long fibres, MSc thesis, University of Minho, Portugal (2001).

[4] Plastics Engineering Europe, Vol. 1, No 2 (2003).

[5] F. Haupert and K. Fredrich: Characterization of the Consolidation and Impregnation Quality of Thermoplastic Filament Wound Composite Rings, ECCM 6, Hamburg, Germany (1994), p. 333-341.

[6] B. Lauke, K. Schnider and K. Friedrich: Interlaminar Shear Strength Measurement of Thin Composite Rings Fabricated by Filament Winding, Proceedings of ECCM 5, France (1992), p. 313-18. 


\section{Advanced Materials Forum V}

doi:10.4028/www.scientific.net/MSF.636-637

\section{Glass/Polyvinyl Chloride Composites}

doi:10.4028/www.scientific.net/MSF.636-637.214

\section{References}

[1] The Research Requirements of the Transport Sectors to Facilitate an Increased Usage of Composite Materials, Part I - The composite materials research requirements of the aerospace industry, EADS Deutschland GmbH (2004).

[2] The Research Requirements of the Transport Sectors to Facilitate an Increased Usage of Composite Materials, Part I - The Composite Materials Research Requirements of the Automotive Industry, Centro Ricerche Fiat (2004).

[3] S. C. Fonseca: Characterization of Interfaces in Thermoplastic Composites Reinforced with Long fibres, MSc thesis, University of Minho, Portugal (2001).

[4] Plastics Engineering Europe, Vol. 1, No 2 (2003).

[5] F. Haupert and K. Fredrich: Characterization of the Consolidation and Impregnation Quality of Thermoplastic Filament Wound Composite Rings, ECCM 6, Hamburg, Germany (1994), p. 333-341.

[6] B. Lauke, K. Schnider and K. Friedrich: Interlaminar Shear Strength Measurement of Thin Composite Rings Fabricated by Filament Winding, Proceedings of ECCM 5, France (1992), p. 313-18. 